\title{
Fast photosynthesis measurements for phenotyping photosynthetic capacity of rice
}

Tingting Du, Ping Meng, Jianliang Huang, Shaobing Peng and Dongliang Xiong ${ }^{*}$ (D)

\begin{abstract}
Background: Over the past decades, the structural and functional genomics of rice have been deeply studied, and high density of molecular genetic markers have been developed. However, the genetic variation in leaf photosynthesis, the most important trait for rice yield improvement, was rarely studied. The lack of photosynthesis phenotyping tools is one of the bottlenecks, as traditional direct photosynthesis measurements are very low-throughput, and recently developed high-throughput methods are indirect measurements. Hence, there is an urgent need for a fast, accurate and direct measurement approach.
\end{abstract}

Result: We reported a fast photosynthesis measurement (FPM) method for phenotyping photosynthetic capacity of rice, which measures photosynthesis of excised tillers in environment-controlled lab conditions. The light response curves measured using FPM approach coped well with that the curves measured using traditional gas exchange approach. Importantly, the FPM technique achieved an average throughput of 5.4 light response curves per hour, which was 3 times faster than the 1.8 light response curves per hour using the traditional method. Tillers sampled at early morning had the highest photosynthesis, stomatal conductance and the lowest variability. In addition, even $12 \mathrm{~h}$ after sampling, there was no significant difference of photosynthesis rate between excised tillers and in situ. We finally investigated the genetic variations of photosynthetic traits across 568 F2 lines using the FPM technique and discussed the logistics of screening several hundred samples per day per instrumental unit using FPM to generate a wealth of photosynthetic phenotypic data, which might help to improve the selection power in large populations of rice with the ultimate aim of improving yield through improved photosynthesis.

Conclusions: Here we developed a high-throughput method that can measure the rice leaf photosynthetic capacity approximately 10 times faster than traditional gas exchange approaches. Importantly, this method can overcome measurement errors caused by environmental heterogeneity under field conditions, and it is possible to measure 12 or more hours per day under lab conditions.

Keywords: Phenotyping, Photosynthetic capacity, Gas exchange, Genetic variation, Light response curve, Rice

\section{Background}

Crop yields must increase dramatically to feed the growing global population $[19,22]$. Carbon assimilation rate is a major productivity-related trait that has

*Correspondence: dlxiong@mail.hzau.edu.cn

National Key Laboratory of Crop Genetic Improvement, MOA Key Laboratory of Crop Ecophysiology and Farming System in the Middle Reaches of the Yangtze River, Huazhong Agricultural University, Wuhan 430070, Hubei, China yet to be improved [6,24, 47], and the overarching reason is our inability to efficiently screen large numbers of plants $[29,34]$. To meet the rapid growth of global food requirement, high-throughput phenotyping of photosynthesis method must be developed. Recently, some high-throughput approaches, such as thermal imagery, hyperspectral reflectance, chlorophyll fluorescence, normalized difference vegetation index (NDVI) and infrared thermography, have been developed for studying photosynthesis [8, 12, 33]. However, these approaches

(c) The Author(s) 2020. This article is licensed under a Creative Commons Attribution 4.0 International License, which permits use, sharing, adaptation, distribution and reproduction in any medium or format, as long as you give appropriate credit to the original author(s) and the source, provide a link to the Creative Commons licence, and indicate if changes were made. The images or other third party material in this article are included in the article's Creative Commons licence, unless indicated otherwise in a credit line to the material. If material is not included in the article's Creative Commons licence and your intended use is not permitted by statutory regulation or exceeds the permitted use, you will need to obtain permission directly from the copyright holder. To view a copy of this licence, visit http://creativeco mmons.org/licenses/by/4.0/. The Creative Commons Public Domain Dedication waiver (http://creativecommons.org/publicdomain/ zero/1.0/) applies to the data made available in this article, unless otherwise stated in a credit line to the data. 
are typically indirect photosynthesis measurements, and some of them are challenging to operate in the field. As the relationships between photosynthetic indexes based on indirect approaches and photosynthetic rate are far from "direct", these approaches require calibration and validation against direct photosynthesis measurements [28].

Leaf gas exchange measurement is a direct way to evaluate the photosynthetic capacity of a plant [23]. All leaf gas exchange systems work by enclosing an entire or part of a leaf within a cuvette. The differences in $\mathrm{CO}_{2}$ and vapor concentration (generally determined using an infra-red gas analyzer, IRGA) between the 'reference' air flow that enters the cuvette and the 'sample' air flow that exits the cuvette are used to calculate the rates of photosynthesis (or respiration) and transpiration. By recording other environmental parameters, some photosynthetic parameters, for instance, stomatal conductance and $\mathrm{CO}_{2}$ concentration in the intercellular air space, can be calculated [10,37]. For most of the commercial gas exchange systems, the quantity and quality of the light, flow rate of air, air humidity, temperature, and concentration of atmospheric gases can be controlled to determine the photosynthetic response of the area of leaf contained within the cuvette. Using these systems, light- and $\mathrm{CO}_{2}$ response curves can also be estimated to provide photosynthetic mechanistic information [23]. However, photosynthesis is sensitive to environment changes. To obtain the comparable measurements for different genotypes and/or treatments, gas exchange measurements are typically conducted under controlled conditions, requiring a long time for a leaf inside the cuvette to acclimate to the new environmental conditions [15]. In addition, precise controlling of the environment inside cuvettes, especially, temperature and humidity, requires a relatively stable ambient environment; hence, in most case, gas exchange measurement can only be performed within a short period under field conditions. Increasing throughput requires a large number of units, which is very expensive. Furthermore, some crops grow in special conditions, making it very difficult to perform gas exchange measurement in situ. For instance, rice, a staple food of more than half the world's population, grows in flooded conditions (Fig. 1).

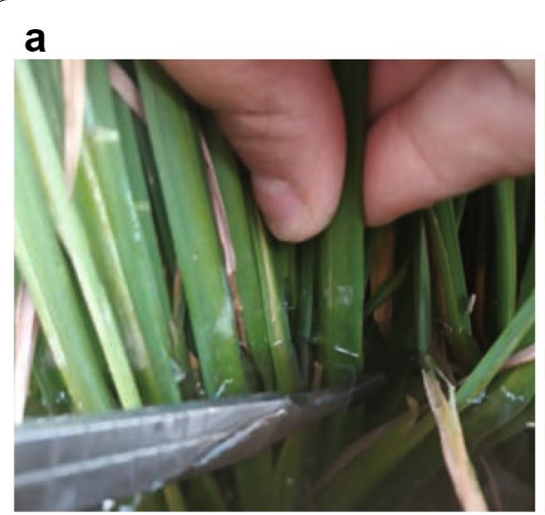

d

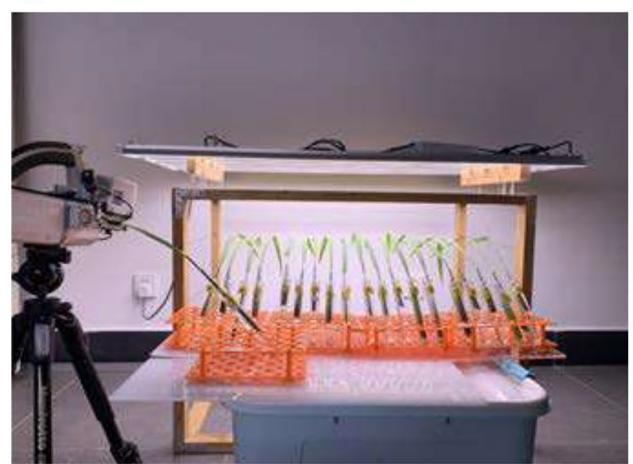

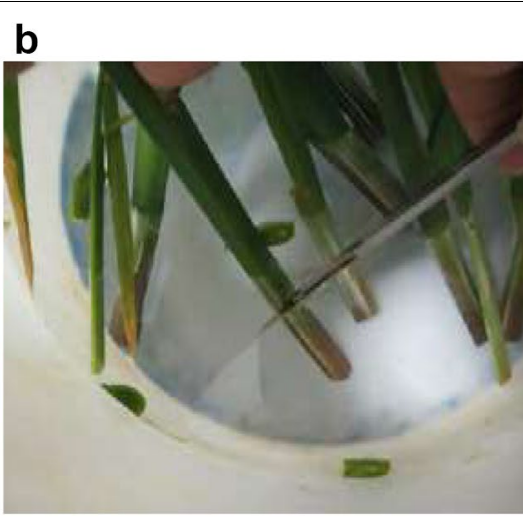

e

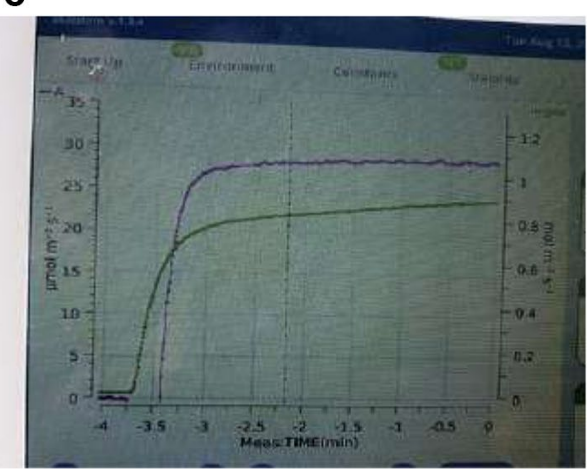

c

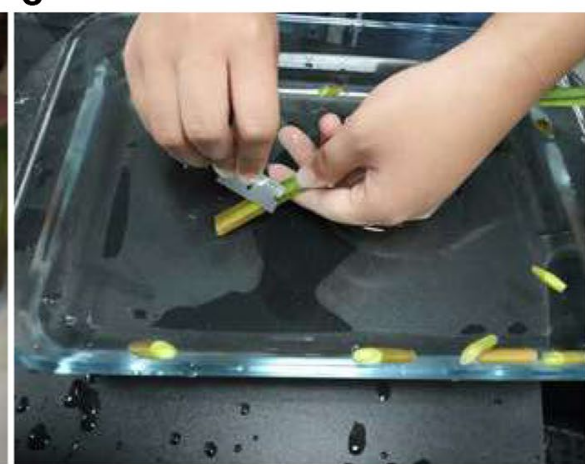

f

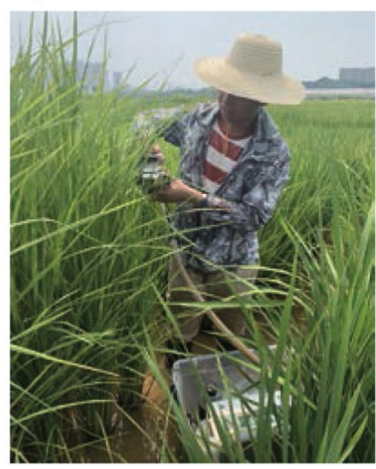

Fig. 1 Photographs of the FPM technique (a-e) and gas exchange measurements in a flooded field ( $f$ ). a Tillers were first cut under field water; $\mathbf{b}$ tillers were immediately transferred to airless distilled water, and a second-cut was created under water; $\mathbf{c}$ tillers were re-cut under airless distilled water after removing all the non-target region; $\mathbf{d}$ leaves were illuminated using a LED light source before performing gas exchange measurement (photosynthetic photo flux density $=1500 \mu \mathrm{mol} \mathrm{m}^{-2} \mathrm{~s}^{-1}$ ); e sample the fast gas exchange measurement using a Li-6800; $\mathbf{f}$ typical gas exchange measurement in a flood rice field. See details in the text 
Here we present a fast photosynthesis measurement (FPM) method that reduces the time necessary to measure an instantaneous point gas exchange measurement of rice leaves to less than $2 \mathrm{~min}$, making it possible to screen several hundreds of leaves per day with a single gas exchange system. We finally applied FPM to a F2 population to investigate the genetic variation of photosynthetic traits.

\section{Results}

\section{Excised vs in situ tillers}

Light response curves of excised and in situ tillers were estimated using HHZ and LYPJ grew in the field and in pot conditions, respectively (Fig. 2). The light response curves of excised tillers and in situ tillers were similar in shape, and no difference in photosynthetic rates $(A)$ were observed at any light intensity. Moreover, no differences were observed in fitted parameters of light response curves, although the light-saturated photosynthetic rates $\left(A_{\text {sat }}\right)$ of excised tillers were slightly elevated in both genotypes. Our results showed that the $A_{\text {sat }}$ and light compensation point (LCP) of $\mathrm{HHZ}$ was higher than LYPJ, but no difference in light intensity was detected under $75 \%$ saturated photosynthesis. To investigate the impacts of storage time of excised tillers in the lab on gas exchange measurements, photosynthesis of excised tillers that were maintained in the lab for 1 to $24 \mathrm{~h}$ were measured. Although the photosynthetic rate of excised tillers declined with storage time, no significant differences in photosynthetic rate were found between excised tillers from any storage time and in situ plants (Fig. 3).

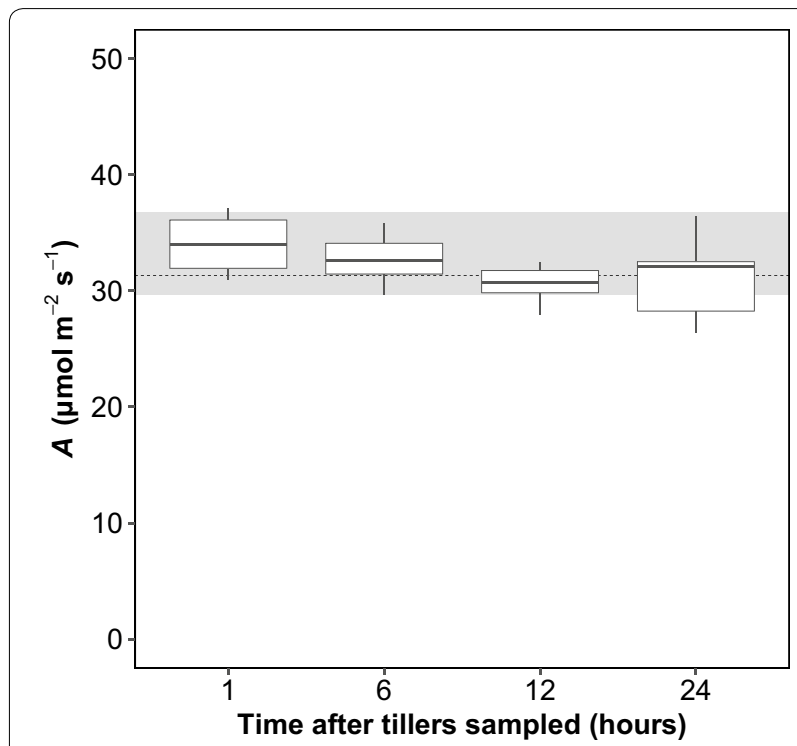

Fig. 3 Influence of the storage time of excised tillers on photosynthesis (A). All the tillers were sampled in the early morning, and tillers for fast gas exchange measurements were prepared as described in the text. The shaded area and dotted line indicate the interquartile range (IQR) and median value of in situ $A$, respectively. In-situ $A$ measured under field conditions in the early morning and using the traditional approach (see details in the text). $N=10$

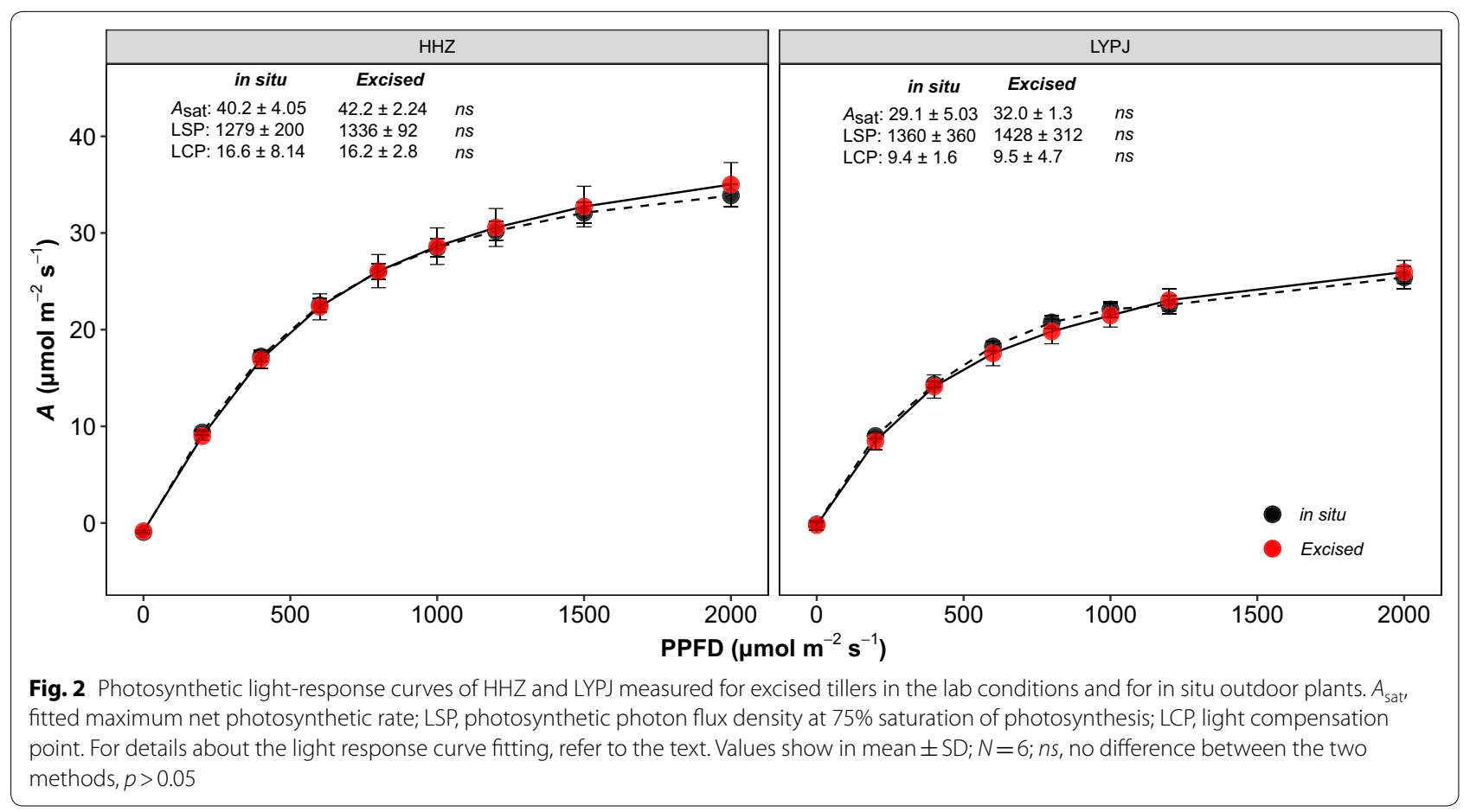




\section{Effects of sampling time and illumination time on photosynthesis}

To investigate the influences of sampling time on photosynthesis of excised tillers, the gas exchange of tillers $(\mathrm{N}=10)$ excised at different times during the day was measured. We found that the tillers sampled in the early morning had the highest $A$ and stomatal conductance to vapor $\left(g_{\mathrm{sw}}\right)$, and moreover, the variabilities of $A$ and $g_{\mathrm{sw}}$ were lower in tillers sampled in early morning and at end of the day (6:00 and 18:00) than those sampled at midday (Fig. 4). Interestingly, the leaf water potential showed the same pattern as $A$ and $g_{\text {sw. }}$.

To test the accommodation time effects, a fast gas exchange measurement was performed to excised tillers with different adaptation times and light intensities combinations in the lab condition. We showed that rice leaves achieved maximum photosynthetic rates within 10 min under all three light intensities (Fig. 5). Unlike photosynthetic rate, more than 20 min were needed for tillers to fully open their stomata. The tillers exposed to $1500 \mu \mathrm{mol} \mathrm{m}^{-2} \mathrm{~s}^{-1}$ photosynthetic photon flux density (PPFD) had the highest stabilized photosynthetic rate and stomatal conductance.

\section{Genetic variation of photosynthesis}

The genetic variations of gas exchange and chlorophyll content of 568 F2 lines and their parental lines YD6 and N22 were investigated over 2 days using the FPM technique. Among the F2 populations, the $A$ and $g_{\text {sw }}$ varied from 7.2 to $34.76 \mu \mathrm{mol} \mathrm{m} \mathrm{m}^{-2} \mathrm{~s}^{-1}$ and 0.081 to $1.53 \mathrm{~mol} \mathrm{~m}^{-2} \mathrm{~s}^{-1}$, with means of $21.03 \mu \mathrm{mol} \mathrm{m} \mathrm{m}^{-2}$ $\mathrm{s}^{-1}$ and $0.69 \mathrm{~mol} \mathrm{~m}^{-2} \mathrm{~s}^{-1}$, respectively (Fig. 6). The two parental lines, YD6 and N22, had $A$ of $31.7 \pm 1.04$ and $25.8 \pm 1.04 \mu \mathrm{mol} \mathrm{m}^{-2} \mathrm{~s}^{-1}, g_{\mathrm{sw}}$ of $0.92 \pm 0.11$ and
$0.94 \pm 0.08 \mathrm{~mol} \mathrm{~m}^{-2} \mathrm{~s}^{-1}$, respectively (mean \pm standard error $(\mathrm{SE}), \mathrm{n}=20)$. Mesophyll conductance $\left(g_{\mathrm{m}}\right)$, varied tenfold, from 0.051 to $0.51 \mathrm{~mol} \mathrm{~m}^{-2} \mathrm{~s}^{-1}$, with a mean of $0.21 \mathrm{~mol} \mathrm{~m}^{-2} \mathrm{~s}^{-1}$. The two parental lines, YD6 and N22, had $g_{\mathrm{m}}$ of $0.414 \pm 0.024$ and $0.228 \pm 0.019 \mathrm{~mol} \mathrm{~m}^{-2} \mathrm{~s}^{-1}$ (mean $\pm \mathrm{SE}$ ), respectively. In this study, the maximum carboxylation efficiency $\left(V_{\text {cmax }}\right)$, varied fivefold, from 44.6 to $191.7 \mu \mathrm{mol} \mathrm{m} \mathrm{m}^{-2} \mathrm{~s}^{-1}$, with a mean of $107.8 \mu \mathrm{mol} \mathrm{m}{ }^{-2}$ $\mathrm{s}^{-1}$. The two parental lines YD6 and N22 had $V_{\text {cmax }}$ of $164.2 \pm 6.9$ and $124.7 \pm 5.1 \mu \mathrm{mol} \mathrm{m}{ }^{-2} \mathrm{~s}^{-1}$ (Mean $\pm \mathrm{SE}$ ), respectively. Surprisingly, $g_{\mathrm{sw}}, g_{\mathrm{m}}$ and $A / g_{\mathrm{sw}}$ were skewed from the normal distribution (Additional file 1: Table S1, Additional file 2: Figure S1; Fig. 6). Gas exchange parameters $\left(A, g_{\mathrm{sw}}, V_{\text {camx }}, g_{\mathrm{m}}, A / g_{\mathrm{sw}}\right)$ were significantly correlated with each other, except relationship between $V_{\text {cmax }}$ and $A / g_{\text {sw }}$ (Additional file $3:$ Table S2). $A$ was strongly related to $g\left(A=12.81 g+12.46 ; r^{2}=0.62 ; p<0.001\right)$ and $g_{\mathrm{m}}\left(A=47.80 g_{\mathrm{m}}+11.33 ; r^{2}=0.50 ; p<0.001\right)$ across rice genotypes (Fig. 7). Both of $A$ and $V_{\text {cmax }}$ were significantly related to SPAD.

\section{Discussion}

Instantaneous point measurement of leaf gas exchange is the most widely used technique when assessing the photosynthetic capacity of plants under experimental or natural conditions [13, 26, 43]. Point measurements can be performed under ambient or set conditions of $\mathrm{CO}_{2}$ concentration, light intensity, temperature and humidity within the leaf cuvette of the gas exchange system. As leaves do not need to acclimate to new environmental conditions inside the cuvette, the use of ambient cuvette conditions in the field may be beneficial in terms of an increased speed of measurement [39]. However, variation in environmental conditions, such as light intensity and
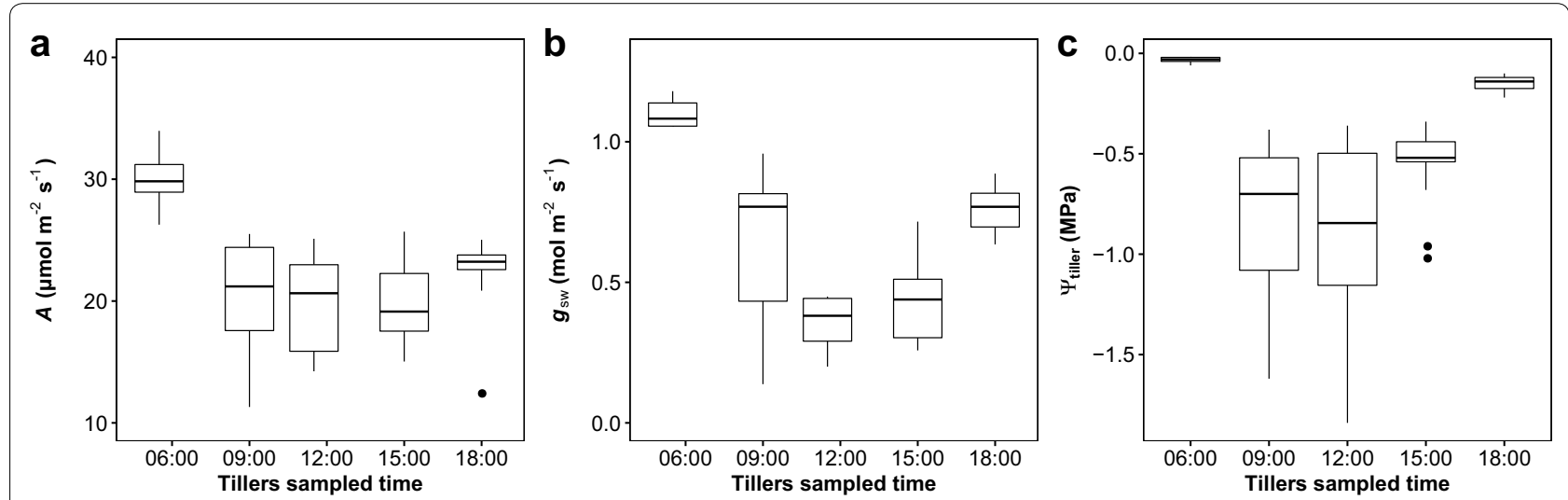

Fig. 4 Gas exchange and water potential of $\mathrm{HHZ}$ tillers sampled at different times during a day. a Photosynthetic rate, $\mathbf{b}$ stomatal conductance to vapor, and $\mathbf{c}$ leaf water potential. Tillers for gas exchange measurements were prepared as described in the text and kept in the dark for 1 to 2 $\mathrm{h}$ before exposure to light for acclimation. Tillers for water potential measurement were equilibrated in double bags in the dark for 25 min after sampling. $N=10$ 

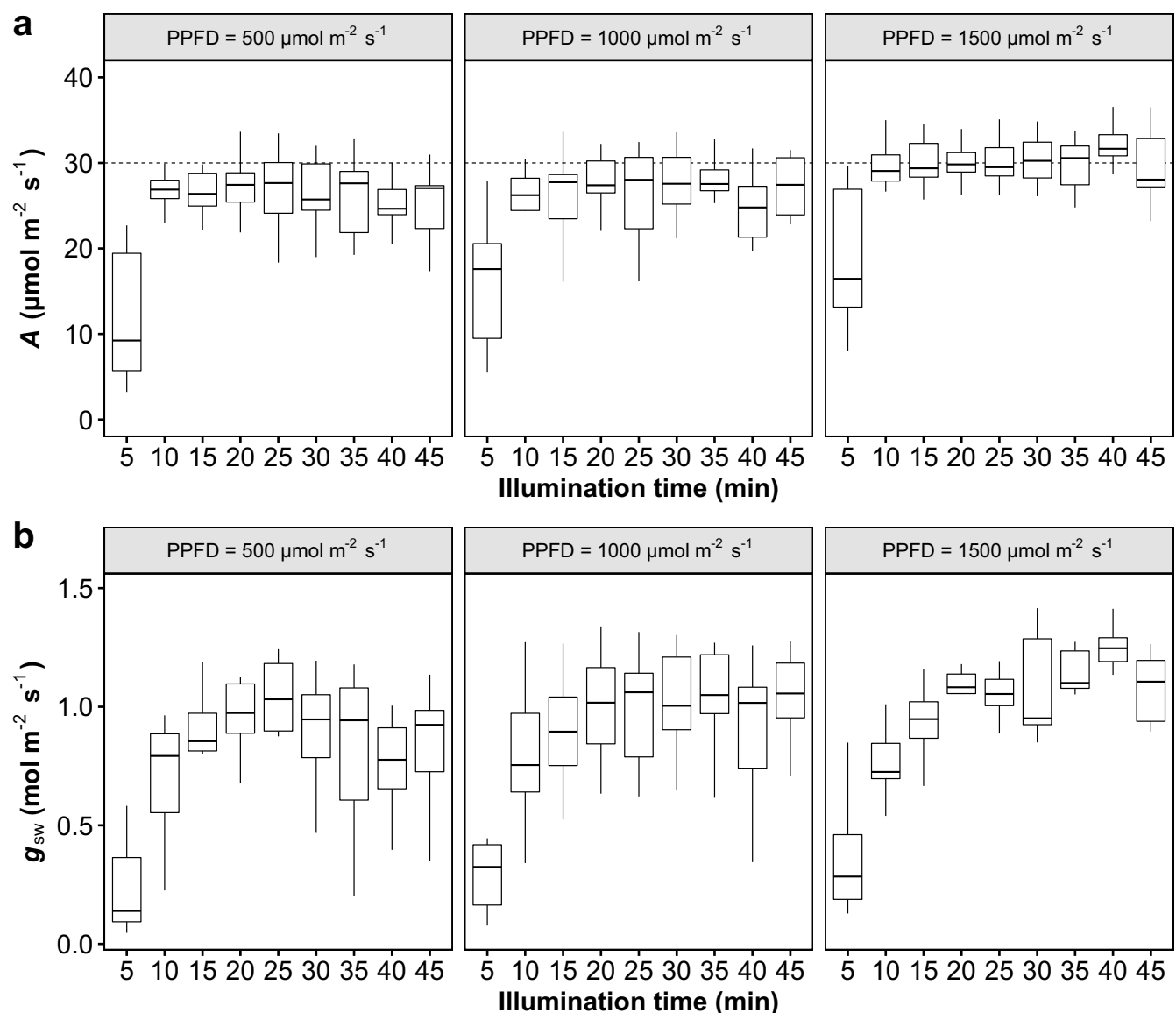

Fig. 5 Effects of the illumination time and light intensity on a the photosynthetic rate (A) and $\mathbf{b}$ stomatal conductance to vapor $\left(g_{\mathrm{sw}}\right)$ of excised tillers. The tillers were sampled in the early morning and kept in the dark before exposure to light. The photosynthetic photon flux density inside the gas exchange cuvette was $1500 \mu \mathrm{mol} \mathrm{m}{ }^{-2} \mathrm{~s}^{-1}$ for all the measurements. $N=10$

air temperature, influence consistency between measurements $[3,18,25]$. Instantaneous point measurements under set controlled cuvette conditions generally require a long time for leaves to acclimate to the new conditions within the leaf cuvette [46]. A maximum rate of 30 measurements per day per gas exchange unit has been practically confirmed in environmentally controlled growth chambers [1], and much fewer measurements can be accomplished in field conditions due to the heterogeneity of environmental factors over the day and/or circadian regulation [29]. In fact, it is preferable to conduct gas exchange measurements in a short-term period (i.e., between 9:00 and 11:30 am) on clear sunny days under field conditions, which restricts the throughput and repeatability of gas exchange measurements in traditional approaches. Here, more than 300 robust gas exchange measurements were performed per day per LI-6800. Although FPM is a destructive approach, it can overcome the diurnal variations and/or environmental changes that introduce errors in light-saturated photosynthetic capacity investigations (Fig. 3), and it is possible to perform the measurements for $12 \mathrm{~h}$ or more hours per day. The FPM technique's success is mainly attributed to that it allows the leaves to acclimate to saturating light after darkness equilibrium under environmentally controlled lab condition.

Light response and $\mathrm{CO}_{2}$ response curves are two widely used measurements that provide mechanistic information, such as quantum yield, daytime respiration and photosynthetic biochemical limitations [32, 44, 45]. However, these measurements are time-consuming: 1 to 3 curves (depending on the system, number of steps and ambient conditions) per hour under field conditions. Similar to the instantaneous point measurements under set controlled cuvette conditions, delays for acclimation to the controlled environment inside the cuvette represent the bottleneck of the throughput. We achieved an average throughput of 5.4 light response curves per hour-3 times greater than the 1.8 light response curves per hour possible using the traditional method in the 

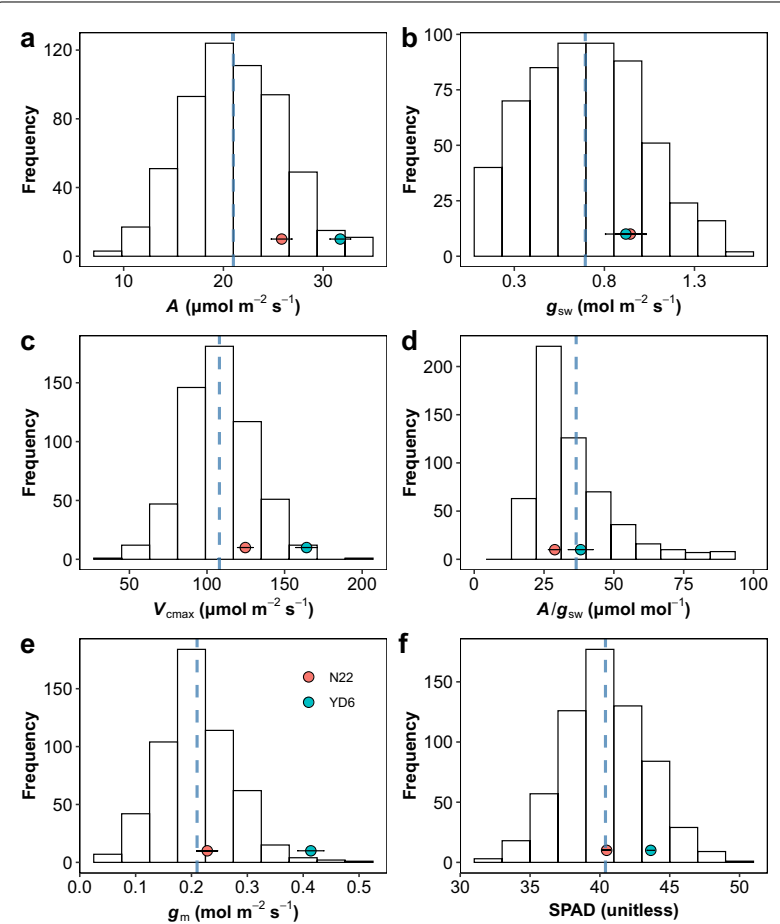

Fig. 6 Frequency distributions of the leaf gas exchange parameters and leaf chlorophyll content (a photosynthetic rate; b stomatal conductance to vapor; c maximum rate of carboxylation; $\mathbf{d}$ leaf intrinsic water use efficiency; e mesophyll conductance to $\mathrm{CO}_{2}$; f leaf chlorophyll content) of 568 F2 lines. Mean values with SDs of the parental lines $(N=20)$ YD6 and N22 are indicated. The dotted line indicates the mean value of $\mathrm{F} 2$ lines

rice field, but with the same data quality (Fig. 2). Importantly, the gas exchange measurements can only be conducted between 9:00 and 12:00 on sunny days using the traditional approach, due to the midday depression of photosynthesis [27] and/or the heterogeneity of environmental conditions throughout the day. In contrast, whole day measurements are possible using the FPM approach (Fig. 3).

\section{Answers and further research questions arising from the FPM technique}

In this study, we also observed some interesting biological behaviors which were generally ignored in the past. First, we found that the gas exchange of excised tillers was highly dependent on the sampling time (Fig. 4). The photosynthesis and stomatal conductance were significantly lower for the tillers sampled during the day than in early morning. The decline of the gas exchange rate could be, at least partly, explained by the changes in plant water potential. When the tiller water potential is quite low $(-1.9$ to $-0.45 \mathrm{MPa}$ in this study), the released tension of xylem caused by tiller excision may introduce cavitation in the xylem, therefore restricting water transportation in the plant [36]. Although the excised tillers were cut under water, cavitation might be caused by the thin gas film on the razor blade surface. Refilling under low transpiration conditions is considered an efficient approach to remove cavitation in the xylem; however, recent studies have suggested that embolic xylem is unable to recover even when kept in darkness [7, 17]. If cavitation is the casual factor, then current approaches for leaf and stem hydraulic capacity estimation are dubious, at least for rice, as tillers are typically sampled during the day. Unfortunately, in this study, cavitation was not estimated because it was not tightly related to the key questions that arose in this study, necessitating further estimations.

Second, gas exchange measurements were affected by the light intensity gradients between the inside and
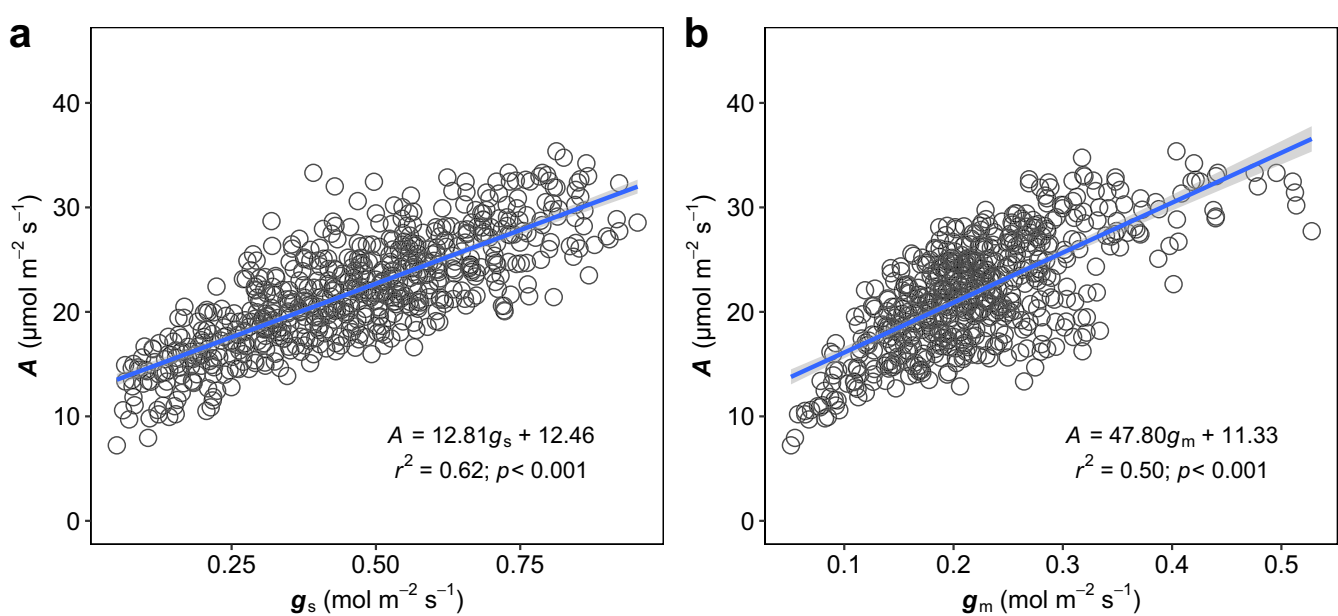

Fig. 7 Correlation between the photosynthetic rate $(A)$ and $\mathbf{a}$ stomatal conductance to $\mathrm{CO}_{2}\left(g_{\mathrm{s}}\right)$ and $\mathbf{b}$ mesophyll conductance to $\mathrm{CO}_{2}\left(g_{\mathrm{m}}\right)$ across F2 lines 
outside of the gas exchange cuvette (Fig. 5). The leaves that had adapted to 1000 or $500 \mu \mathrm{mol} \mathrm{m}{ }^{-2} \mathrm{~s}^{-1}$ photosynthetic photon flux density had a low $A$ compared with leaves that had adapted to $1500 \mu \mathrm{mol} \mathrm{m}{ }^{-2} \mathrm{~s}^{-1}$ photosynthetic photon flux density. One possible explanation for this finding is that plants may have the ability to optimize their photosynthetic enzymes to acclimate to a given ambient light condition, and a long time is required to acclimate to a new light environments [20,30]. Another candidate mechanism may be related to the light dependence of mesophyll conductance, which has been widely observed in the past decades $[4,5,35,42]$. Again, although those candidate mechanisms were not investigated in the current study, this information is important to improve understanding of the light responses of photosynthesis and to measure gas exchange accurately, as current light-saturated photosynthesis measurements are typically estimated under dynamic light conditions.

\section{Limitations of FPM and potential improvements}

Just as traditional gas exchange approaches are not optimized for throughput, FPM is not optimized for many experimental situations. First, the FPM approach is not suitable to estimate gas exchange for water-controlled plants. Second, stomatal conductance estimated using the FPM approach was slightly higher compared with the values estimated using the traditional in situ approach. Stomatal conductance has been suggested to be limited by the leaf water potential; however, the excised tillers assimilated water through the cut surface of the stem where the water potential was nearly zero and therefore potentially increased the leaf water potential. However, the water potential issue could be partly solved using plural osmotica (i.e. artificial xylem sap) to simulate the natural stem water potential. Third, FPM is likely unable to estimate the natural diurnal variations of gas exchange in the current stage because leaves are acclimated to the environmentally controlled lab conditions. Finally, due to lack of root, the functions of the root systems in gas exchange cannot be evaluated.

\section{Genetic variation of rice photosynthesis}

In this study, by using the FPM technique, we investigated the rice genetic variations of photosynthetic traits, including $A, g_{\mathrm{s}}, g_{\mathrm{m}}$ and $V_{\mathrm{cmax}}$, across $568 \mathrm{~F} 2$ lines. Although quantitative trait locus (QTL) analysis was not performed, QTL and/or genome-wide association study (GWAS) analysis to photosynthetic traits are possible using the FPM technique to phenotype photosynthetic traits. We did not perform QTL analysis in the present study due to the absence of: (1) a genetic map for the population, currently and (2) biological replicates for each line because the F2 individuals are heterozygous.
Six gas exchange related traits were detected and most of their distribution were approximately $(p>0.01$; Additional file 1: Table S1) normal distribution except $A / g_{\text {sw }}$. The negatively skewed ' $A / g_{\text {sw }}$ ' is mainly because of the positively skewed $g_{\text {sw }}$ distribution. Great variations among F2 lines were observed, but only a few genotypes had a slightly higher the photosynthetic rate than the parent YD6. As YD6 has been the most widely used parental line for super rice breeding in China over the past decades, its photosynthetic assimilation rate may have already been selected by breeders. Moreover, both stomatal and mesophyll conductance were tightly correlated to the photosynthetic rate among genotypes (Fig. 7). Correlations between conductance and photosynthetic rate are often observed (see a recent meta-analysis [40] and references therein), and the $\mathrm{CO}_{2}$ concentration within the chloroplast is considered a target trait for a high rate of photosynthesis [11].

\section{Conclusions}

The methodology described herein elucidates a fast, high throughput approach, FPM, for phenotyping photosynthetic capacity in a major crop species under lab conditions. We demonstrated that excised tillers can be used as a robust proxy for leaf gas exchange estimation. Furthermore, we discussed the advantages and disadvantages of FPM. Finally, we investigated the genetic variations of photosynthetic traits across 568 F2 lines using the FPM technique and discussed the logistics of screening several hundred samples per day per instrumental unit using FPM to contribute a wealth of photosynthetic phenotypic data and improve selection power in large populations of rice, with the ultimate aim of improving yield through improved photosynthesis.

\section{Methods \\ Plant materials}

Oryza sativa, cv Huanghuazhan (HHZ) and Liangyoupeijiu (LYPJ) were used to establish the FPM. HHZ is a widely cultivated local inbred variety and LYPJ is a famous hybrid rice cultivar in China. HHZ seedlings, 25 days after sowing in the nursery, were transplanted into a paddy field (Huazhong Agricultural University, Wuhan, Hubei, China) at a plant density of $33.3 \times 33.3 \mathrm{~cm}$. The compound fertilizer $\left(\mathrm{N}: \mathrm{P}_{2} \mathrm{O}_{5}\right.$ : $\mathrm{K}_{2} \mathrm{O}=16 \%$ : 16\%: 16\%; Batian Ecological Engineering Limited, Shenzhen, China) at a rate of $375 \mathrm{~kg} \mathrm{ha}^{-1}$ was applied to the field 2 days before transplanting, and urea at a rate of $100 \mathrm{~kg} \mathrm{ha}^{-1}$ was applied 2 weeks after transplanting. Herbicides, pesticides and germicides were applied regularly to avoid any stress. LYPJ plants were grown in outdoor pot conditions on Huazhong Agricultural University campus. Twenty-two-days-old seedlings 
of LYPJ were transplanted into $11 \mathrm{~L}$ pots containing $10 \mathrm{~kg}$ dry soil mixed with $0.51 \mathrm{~g}$ urea, $1.96 \mathrm{~g}$ superphosphate and $0.28 \mathrm{~g}$ potash muriate. Nitrogen topdressing was applied 2 weeks after transplanting ( $0.39 \mathrm{~g}$ urea per pot). Each pot contained three seedlings, and there were 48 pots. The visible water layer was maintained during the experiment by daily watering.

The F2 populations, derived from a reciprocal cross between Yangdao 6 (YD6) and N22, were grown under field conditions to access the throughput of PFM. YD6 is a parent of many super rice cultivars that have been released in past decades in China, and N22 is an abiotic stress tolerance genotype [16,31]. Our preliminary experiment results showed that $A_{\text {sat }}$ of YD6 was higher than N22. The F2 populations were grown in the same field plot as HHZ and with equivalent all management practices.

\section{Tiller preparation for FPM in the lab}

The tiller preparation process is shown in Fig. 1. In short, the main tillers at the panicle initiation stage were first cut using a new razor blade under paddy water, and the cut surface of the tillers was immediately transferred to airless distilled water and cut a second time under water. The tillers were then covered with double black bags and transferred to the lab (approximately $1000 \mathrm{~m}$ from the experimental field). In the lab, all the non-target leaves were removed from the stem to ensure perfect illumination of the target leaves, and the tillers were recut under airless distilled water. Finally, the cut surface of a single tiller was transferred to a 25-ml glass tube filled with airless distilled water under water and maintained in the lab (air temperature, $28{ }^{\circ} \mathrm{C}$; relative humidity, $50 \%$; PPFD $<10 \mu \mathrm{mol} \mathrm{m}{ }^{-2}$ $\mathrm{s}^{-1}$ ). All the tillers, except for the sample time test samples, were harvested from the plants prior to 06:40 (dawn time between 05:40 and 05:51 during the experiment). For the genetic variation experiment, $295 \mathrm{~F} 2$ tillers of YN $($ YD6 $\times$ N22), $273 \mathrm{~F} 2$ tillers of NY $(\mathrm{N} 22 \times$ YD6) and ten tillers of each parent were harvested before 06:40 from the field. Before performing the gas exchange measurements, the target leaf area was illuminated with $1500 \mu \mathrm{mol} \mathrm{m}{ }^{-2}$ $\mathrm{s}^{-1}$ (estimated using Li190SB, Li-COR Inc., Lincoln, NE, USA) for $30 \mathrm{~min}$ to achieve a photosynthetic stable status using a LED light source (Weichuang Electronic Technology Limit, Wuhan, China).

\section{Gas exchange measurements}

Gas exchange was estimated using a LI-6800 (Li-COR Inc., Lincoln, NE, USA). To minimize gradients between lab ambient conditions and inside the cuvette of the gas exchange system, the sample $\mathrm{CO}_{2}$ concentration, relative humidity and leaf temperature inside the cuvette were set to $400 \mu \mathrm{mol} \mathrm{mol}{ }^{-1}, 65 \%$ and $28{ }^{\circ} \mathrm{C}$, respectively. Light response (AQ) curves of $\mathrm{HHZ}$ and LYPJ were generated on excised tillers in the lab conditions, and in situ plants in pots or field conditions. Based on the light response curve results, the PPFD inside the LI-6800 cuvette was set to $1500 \mu \mathrm{mol} \mathrm{m}^{-2} \mathrm{~s}^{-1}$ for photosynthesis measurements. As a great number of plants are required to test sampling time and illumination time effects, only the HHZ plants grown in the field condition were used in these tests. Leaves were held in the cuvette until the photosynthesis values were stable, i.e., 'steady state', which generally occurred rapidly ( $\sim 30 \mathrm{~s})$ due to the similarity of the conditions inside and outside the leaf chamber. Typically, measurements were collected if the changes in photosynthetic rate were less than $0.5 \%$ over 1 min (Fig. 1 ). Outdoor in situ gas exchange estimation was conducted between $8: 30$ and 11:30 using the (standard) traditional approach. The environmental conditions inside the cuvettes were set as above, and before recording the gas exchange data, at least 20 min were generally required to achieve a stable gas exchange measurement (photosynthetic rate variation of less than $0.5 \%$ in $1 \mathrm{~min}$ ).

For population materials, leaf gas exchange and chlorophyll fluorescence were measured simultaneously. The electron transport rate $(J)$ was then calculated as follows:

$$
J=\Phi_{\mathrm{PSII}} \cdot \operatorname{PPFD} \cdot \alpha \beta,
$$

where, $\Phi_{\text {PSII }}$ is the actual photochemical efficiency of photosystem II, $\alpha$ is the leaf absorptivity and $\beta$ is the partitioning of absorbed quanta between photosystems II and I. In the current study, the $\alpha \beta$ value of 0.44 was used based on the previous studies [38, 41].

The variable $J$ method [14] was used to calculate $g_{\mathrm{m}}$ :

$$
g_{\mathrm{m}}=\frac{A}{C_{i}-\frac{\Gamma^{*}\left(J+8\left(A+R_{\mathrm{d}}\right)\right)}{J-4\left(A+R_{\mathrm{d}}\right)}},
$$

where $A$ is the photosynthetic rate at PPFD of $1500 \mu \mathrm{mol} \mathrm{m} \mathrm{m}^{-2} \mathrm{~s}^{-1}, C_{\mathrm{i}}$ is the $\mathrm{CO}_{2}$ mol fraction in the intercellular air space, $\Gamma^{\prime \prime}$ represents the $\mathrm{CO}_{2}$ compensation point in the absence of mitochondrial respiration and $R_{\mathrm{d}}$ is the daytime respiration rate. Typical values of $40 \mu \mathrm{mol} \mathrm{mol}^{-1}$ and $1 \mu \mathrm{mol} \mathrm{m}{ }^{-2} \mathrm{~s}^{-1}$ were used for $\Gamma^{*}$ and $R_{\mathrm{d}}$, respectively [38]. For each data point generated, we checked whether it met the criterion $\left(10>d C_{\mathrm{c}} / d A>50\right)$ [14].

The 'one-point' method [9] was used to calculate $V_{\text {cmax }}$ :

$$
V_{\mathrm{cmax}}=A\left(\frac{C_{\mathrm{i}}+K_{\mathrm{m}}}{C_{\mathrm{i}}-\Gamma^{*}}-0.015\right),
$$

where $K_{\mathrm{m}}$ is apparent Michaelis constant for carboxylation which was calculated: 


$$
K_{\mathrm{m}}=K_{\mathrm{c}}\left(1+\frac{O_{\mathrm{i}}}{K_{\mathrm{o}}}\right)
$$

where $K_{\mathrm{c}}$ is Michaelis constant for carboxylation, and $K_{\mathrm{O}}$ is Michaelis constant for oxygenation, $O_{\mathrm{i}}$ is oxygen content in the intercellular air space. We chiefly use values taken from [2] calibrated to $25^{\circ} \mathrm{C}$.

\section{Chlorophyll content and leaf water potential}

In this study, the dynamic of water potential during the day was estimated using a pressure chamber (Soil Moisture Equipment Crop., Santa Barbara, Ca., USA). Tillers were double bagged shortly after sampling and kept in a cool box for 25 min for equilibration. Chlorophyll content was measured using SPAD 502 (Konica Minolta, Japan). Eight points were measured in 5 -cm longitudinal distance in the middle of the leaf after the gas exchange measurement, and the values were averaged.

\section{Data analysis}

Light response curve parameters, including the maximum net photosynthetic rate $\left(A_{\mathrm{sat}}\right)$, light compensation point (LCP) and PPFD at the $75 \%$ saturation photosynthetic rate (LSP) were fitted using the nonrectangular hyperbola-based model [21]:

$$
A=\frac{\Phi \times \text { PPFD }+A_{\text {gmax }}-\sqrt{\left(\Phi \times \text { PPFD }+A_{\text {gmax }}\right)^{2}-4 \theta \times \Phi \times \operatorname{PPFD} \times A_{\text {gmax }}}}{4 \theta}-R_{\mathrm{n}}
$$

where $\Phi$ is the quantum yield at PPFD $=0 \mu$ mol (photon) $\mathrm{m}^{-2} \mathrm{~s}^{-1}, A_{\text {gmax }}$ is the maximum gross photosynthetic rate, $\theta$ is the convexity factor, and $R_{\mathrm{n}}$ is dark respiration. The model was fitted to the data using the Orthogonal Nonlinear Least-Squares Regression (onls) function. Other analyses and plots were conducted using the tidyverse $\mathrm{R}$ package. All analyses were performed in R 3.6.0.

\section{Supplementary information}

Supplementary information accompanies this paper at https://doi. org/10.1186/s13007-020-0553-2.

Additional file 1: Table S1. Test of normality (Shapiro-Wilk) for photosynthetic traits of F2 populations. The full name and units of the traits are shown in abbreviations list.

Additional file 2: Figure S1. Normal Q-Q plot of photosynthetic traits.

Additional file 3: Table S2. Correlations between the photosynthetic traits of F2 populations. The full name and units of the traits are shown in abbreviations list. The correlations were estimated by the linear model. *Significant at $5 \%$ level.

\section{Abbreviations}

FPM: fast photosynthesis measurement; HHZ: Oryza sativa cultivar Huanghuazhan; LYPJ: Oryza sativa cultivar Liangyoupeijiu; YD6: Oryza sativa cultivar Yangdao 6; PPFD: photosynthetic photo flux density; QTL: quantitative trait loci analysis; $\Phi_{\text {PSII: }}$ photochemical efficiency of photosystem II; a: light absorptivity of leaf; $\beta$ : distribution of absorbed quanta between photosystems $I I$ and $\mathrm{l} ; g_{\mathrm{m}}$ : mesophyll conductance to $\mathrm{CO}_{2}$ diffusion $\left(\mathrm{mol} \mathrm{m} \mathrm{m}^{-2} \mathrm{~s}^{-1}\right) ; A$ : net photosynthetic rate $\left(\mu \mathrm{mol} \mathrm{m} \mathrm{m}^{-2} \mathrm{~s}^{-1}\right) ; \Gamma^{*}: \mathrm{CO}_{2}$ compensation point in the absence of mitochondrial respiration $\left(\mu \mathrm{mol} \mathrm{mol}^{-1}\right)_{i} \mathrm{~J}$ : electric transport rate $\left(\mu \mathrm{mol} \mathrm{m} \mathrm{m}^{-2} \mathrm{~s}^{-1}\right) ; \mathrm{C}_{\mathrm{i}}: \mathrm{CO}_{2} \mathrm{~mol}$ fraction in the intercellular air space $\left(\mu \mathrm{mol} \mathrm{mol}{ }^{-1}\right)$; $R_{\mathrm{d}}$ : daytime respiration rate $\left(\mu \mathrm{mol} \mathrm{m}^{-2} \mathrm{~s}^{-1}\right) ; V_{\text {cmax }}$ : maximum carboxylation efficiency $\left(\mu \mathrm{mol} \mathrm{m} \mathrm{m}^{-2} \mathrm{~s}^{-1}\right) ; K_{\mathrm{m}}$ : apparent Michaelis constant for carboxylation; $K_{c}$ : Michaelis constant for carboxylation; $O_{j}$ : oxygen content in the intercellular air space $\left(\mu \mathrm{mol} \mathrm{mol}^{-1}\right) ; K_{0}$ : Michaelis constant for oxygenation; $g_{\mathrm{sw}}$ : stomatal conductance to vapor diffusion ( $\left.\mathrm{mol} \mathrm{m} \mathrm{m}^{-2} \mathrm{~s}^{-1}\right) ; g_{\mathrm{s}}$ : stomatal conductance to $\mathrm{CO}_{2}$ diffusion ( $\mathrm{mol} \mathrm{m} \mathrm{m}^{-2} \mathrm{~s}^{-1}$ ); LCP: light composition point $\left(\mu \mathrm{mol} \mathrm{m} \mathrm{m}^{-2} \mathrm{~s}^{-1}\right)$; LSP: PPFD at $75 \%$ saturation photosynthetic point ( $\left.\mu \mathrm{mol} \mathrm{m} \mathrm{m}^{-2} \mathrm{~s}^{-1}\right) ; \Phi$ : quantum yield at PPFD $=0 \mu \mathrm{mol}$ (photon) $\mathrm{m}^{-2} \mathrm{~s}^{-1} ; A_{\text {gmax }}$ : maximum gross photosynthetic rate $\left(\mu \mathrm{mol} \mathrm{m} \mathrm{m}^{-2} \mathrm{~s}^{-1}\right) ; \theta$ : convexity factor; $R_{\mathrm{n}}$ : dark respiration rate $\left(\mu \mathrm{mol} \mathrm{m} \mathrm{m}^{-2} \mathrm{~s}^{-1}\right) ; A_{\text {sat }}$ : maximum net photosynthetic rate in light response curve $\left(\mu \mathrm{mol} \mathrm{m} \mathrm{m}^{-2} \mathrm{~s}^{-1}\right)$

\section{Acknowledgements}

The authors thank Lei Liu, Xiaoxiao Wang, Qiaoyun Zhang, Xianhong Huang, Yang Liu for technical assistance.

\section{Authors' contributions}

TD and PM carried out the research, DX and TD wrote the paper with input from JH and SP, and DX and TD conceived of and developed the method. All authors read and approved the final manuscript.

\section{Funding}

This work was supported by National Natural Science Foundation of China (Nos. 31801290 and 31671620).

\section{Availability of data and materials}

The datasets used and/or analyzed during the current study are available from the corresponding author on reasonable request.

\section{Ethics approval and consent to participate}

Not applicable.

\section{Consent for publication}

Not applicable.

\section{Competing interests}

The authors declare that they have no competing interests.

Received: 16 October 2019 Accepted: 10 January 2020

Published online: 24 January 2020

References

1. Barbour MM, Bachmann S, Bansal U, et al. Genetic control of mesophyll conductance in common wheat. New Phytol. 2016;209:461-5.

2. Bernacchi CJ, Singsaas EL, Pimentel C, et al. Improved temperature response functions for models of Rubisco-limited photosynthesis. Plant Cell Environ. 2001;24:253-9.

3. Berry ZC, Goldsmith GR. Diffuse light and wetting differentially affect tropical tree leaf photosynthesis. New Phytol. 2020;225:143-53.

4. Bond DM, Dennis ES, Finnegan EJ. Hypoxia: a novel function for VIN3. Plant Signal Behav. 2009;4:773-6.

5. Carriqui M, Douthe C, Molins A, Flexas J. Leaf anatomy does not explain apparent short-term responses of mesophyll conductance to light and $\mathrm{CO}_{2}$ in tobacco. Physiol Plant. 2019;165:604-18.

6. Centritto M, Lauteri M, Monteverdi MC, Serraj R. Leaf gas exchange, carbon isotope discrimination, and grain yield in contrasting rice genotypes subjected to water deficits during the reproductive stage. J Exp Bot. 2009;60:2325-39.

7. Charrier G, Torres-Ruiz JM, Badel E, et al. Evidence for hydraulic vulnerability segmentation and lack of xylem refilling under tension. Plant Physiol. 2016;172:1657-68.

8. Cruz JA, Savage LJ, Zegarac R, et al. Dynamic environmental photosynthetic imaging reveals emergent phenotypes. Cell Syst. 2016;2:365-77. 
9. De Kauwe MG, Lin YS, Wright IJ, et al. A test of the 'one-point method'for estimating maximum carboxylation capacity from field-measured, lightsaturated photosynthesis. New Phytol. 2016;210:1130-44.

10. Farquhar G, von Caemmerer SV, Berry J. A biochemical model of photosynthetic $\mathrm{CO}_{2}$ assimilation in leaves of $\mathrm{C}_{3}$ species. Planta. 1980;149:78-90.

11. Flexas J, Diaz-Espejo A, Conesa MA, et al. Mesophyll conductance to $\mathrm{CO}_{2}$ and Rubisco as targets for improving intrinsic water use efficiency in $\mathrm{C}_{3}$ plants. Plant Cell Environ. 2016;39:965-82.

12. Furbank RT, Tester M. Phenomics-technologies to relieve the phenotyping bottleneck. Trends Plant Sci. 2011;16:635-44.

13. Gu J, Yin X, Struik PC, et al. Using chromosome introgression lines to map quantitative trait loci for photosynthesis parameters in rice (Oryza sativa L.) leaves under drought and well-watered field conditions. J Exp Bot. 2012:63:455-69.

14. Harley PC, Loreto F, Di Marco G, Sharkey TD. Theoretical considerations when estimating the mesophyll conductance to $\mathrm{CO}_{2}$ flux by analysis of the response of photosynthesis to $\mathrm{CO}_{2}$. Plant Physiol. 1992;98:1429-36.

15. Haworth M, Marino G, Centritto M. An introductory guide to gas exchange analysis of photosynthesis and its application to plant phenotyping and precision irrigation to enhance water use efficiency. J Water Clim Change. 2018;9:786-808.

16. Jagadish SVK, Muthurajan R, Oane R, et al. Physiological and proteomic approaches to address heat tolerance during anthesis in rice (Oryza sativa L). J Exp Bot. 2010:61:143-56.

17. Johnson KM, Jordan GJ, Brodribb TJ. Wheat leaves embolized by water stress do not recover function upon rewatering. Plant Cell Environ. 2018:41:2704-14

18. Kulmala L, Pumpanen J, Kolari P, et al. Inter- and intra-annual dynamics of photosynthesis differ between forest floor vegetation and tree canopy in a subarctic Scots pine stand. Agr Forest Meteorol. 2019;271:1-11.

19. Lauteri M, Haworth $M$, Serraj R, et al. Photosynthetic diffusional constraints affect yield in drought stressed rice cultivars during flowering. PLOS ONE. 2014;9:e109054.

20. Lawson T, Kramer DM, Raines CA. Improving yield by exploiting mechanisms underlying natural variation of photosynthesis. Curr Opin Biotechnol. 2012;23:215-20.

21. Lobo FA, de Barros MP, Dalmagro HJ, et al. Fitting net photosynthetic light-response curves with Microsoft Excel-a critical look at the models. Photosynthetica. 2013;51:445-56.

22. Long SP. We need winners in the race to increase photosynthesis in rice whether from conventional breeding, biotechnology or both. Plant Cell Environ. 2014:37:19-21.

23. Long SP, Bernacchi CJ. Gas exchange measurements, what can they tell us about the underlying limitations to photosynthesis? Procedures and sources of error. J Exp Bot. 2003;54:2393-401.

24. Long SP, Marshall-Colon A, Zhu XG. Meeting the global food demand of the future by engineering crop photosynthesis and yield potential. Cell. 2015;161:56-66.

25. Matthews JSA, Vialet-Chabrand SRM, Lawson T. Diurnal variation in gas exchange: the balance between carbon fixation and water loss. Plant Physiol. 2017;174:614-23.

26. Ortiz D, Hu J, Salas Fernandez MG. Genetic architecture of photosynthesis in Sorghum bicolor under non-stress and cold stress conditions. J Exp Bot. 2017;68:4545-57.

27. Pons TL, Welschen RA. Midday depression of net photosynthesis in the tropical rainforest tree Eperua grandiflora: contributions of stomatal and internal conductances, respiration and Rubisco functioning. Tree Physiol. 2003:23:937-47

28. Porcar-Castell A, Tyystjarvi E, Atherton J, et al. Linking chlorophyll a fluorescence to photosynthesis for remote sensing applications: mechanisms and challenges. J Exp Bot. 2014;65:4065-95.

29. Salter WT, Gilbert ME, Buckley TN. A multiplexed gas exchange system for increased throughput of photosynthetic capacity measurements. Plant Methods. 2018:14:80.
30. Salter WT, Merchant AM, Richards RA, et al. Rate of photosynthetic induction in fluctuating light varies widely among genotypes of wheat. J Exp Bot. 2019:70:2787-96.

31. Shankar R, Bhattacharjee A, Jain M. Transcriptome analysis in different rice cultivars provides novel insights into desiccation and salinity stress responses. Sci Rep. 2016;6:23719.

32. Sharkey TD, Bernacchi CJ, Farquhar GD, Singsaas EL. Fitting photosynthetic carbon dioxide response curves for $\mathrm{C}_{3}$ leaves. Plant Cell Environ. 2007:30:1035-40.

33. Silva-Perez V, Molero G, Serbin SP, et al. Hyperspectral reflectance as a tool to measure biochemical and physiological traits in wheat. J Exp Bot. 2018;69:483-96.

34. Stinziano JR, Morgan PB, Lynch DJ, et al. The rapid A-Ci response: photosynthesis in the phenomic era. Plant Cell Environ. 2017;40:1256-62.

35. Theroux-Rancourt G, Gilbert ME. The light response of mesophyll conductance is controlled by structure across leaf profiles. Plant Cell Environ. 2017:40:726-40.

36. Torres-Ruiz JM, Jansen S, Choat B, et al. Direct x-ray microtomography observation confirms the induction of embolism upon xylem cutting under tension. Plant Physiol. 2015;167:40-3.

37. von Caemmerer S, Farquhar GD. Some relationships between the biochemistry of photosynthesis and the gas exchange of leaves. Planta. 1981;153:376-87

38. Wang $X$, Wang W, Huang J, et al. Diffusional conductance to $\mathrm{CO}_{2}$ is the key limitation to photosynthesis in salt-stressed leaves of rice (Oryza sativa). Physiol Plant. 2018;163:45-58.

39. Xiong D, Douthe C, Flexas J. Differential coordination of stomatal conductance, mesophyll conductance, and leaf hydraulic conductance in response to changing light across species. Plant Cell Environ. 2018:41:436-50.

40. Xiong D, Flexas J. Leaf economics spectrum in rice: leaf anatomical, biochemical, and physiological trait trade-offs. J Exp Bot. 2018;69:5599-609.

41. Xiong D, Flexas J, Yu T, et al. Leaf anatomy mediates coordination of leaf hydraulic conductance and mesophyll conductance to $\mathrm{CO}_{2}$ in Oryza. New Phytol. 2017;213:572-83.

42. Xiong D, Liu X, Liu L, et al. Rapid responses of mesophyll conductance to changes of $\mathrm{CO}_{2}$ concentration, temperature and irradiance are affected by $\mathrm{N}$ supplements in rice. Plant Cell Environ. 2015:38:2541-50.

43. Xu XM, Li G, Su Y, Wang XL. Effect of weedy rice at different densities on photosynthetic characteristics and yield of cultivated rice. Photosynthetica. 2018;56:520-6.

44. Yin X, Struik PC, Romero $P$, et al. Using combined measurements of gas exchange and chlorophyll fluorescence to estimate parameters of a biochemical $C_{3}$ photosynthesis model: a critical appraisal and a new integrated approach applied to leaves in a wheat (Triticum aestivum) canopy. Plant Cell Environ. 2009;32:448-64

45. Yin X, Sun Z, Struik PC, Gu J. Evaluating a new method to estimate the rate of leaf respiration in the light by analysis of combined gas exchange and chlorophyll fluorescence measurements. J Exp Bot. 2011;62:3489-99.

46. Zait Y, Shapira O, Schwartz A. The effect of blue light on stomatal oscillations and leaf turgor pressure in banana leaves. Plant Cell Environ. 2017:40:1143-52.

47. Zhu XG, Long SP, Ort DR. Improving photosynthetic efficiency for greater yield. Annu Rev Plant Biol. 2010;61:235-61.

\section{Publisher's Note}

Springer Nature remains neutral with regard to jurisdictional claims in published maps and institutional affiliations. 